\title{
INSTRUMENT CALIBRATION PLAN OF THE MAINTENANCE MANAGEMENT DEPARTMENT
}

(Supersedes ORNL/CF-87-326)

J. D. Blanton

M. H. Cooper

A. J. Millet

R. A. Vines

Date Published-October 1990

Prepared by the

OAK RIDGE NATIONAL LABORATORY

Oak Ridge, Tennessee 37831-6285

operated by

MARTIN MARIETTA ENERGY SYSTEMS, INC. for the

U.S. DEPARTMENT OF ENERGY under contract DE-AC05-84OR21400 
CONTENTS

Page

LIST OF FIGURES $\ldots \ldots \ldots \ldots \ldots \ldots \ldots \ldots \ldots \ldots \ldots \ldots \ldots \ldots \ldots \ldots$

ABSTRACT $\ldots \ldots \ldots \ldots \ldots \ldots \ldots \ldots \ldots \ldots \ldots \ldots \ldots \ldots \ldots \ldots \ldots$

1. INTRODUCTION $\ldots \ldots \ldots \ldots \ldots \ldots \ldots \ldots \ldots \ldots \ldots \ldots \ldots$

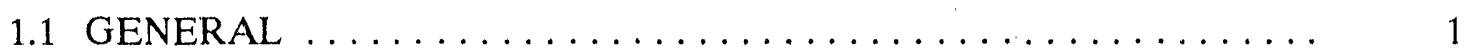

1.2 DEFINITIONS $\ldots \ldots \ldots \ldots \ldots \ldots \ldots \ldots \ldots \ldots \ldots \ldots \ldots \ldots \ldots \ldots \ldots \ldots \ldots$

2. PROGRAM ORGANIZATION $\ldots \ldots \ldots \ldots \ldots \ldots \ldots \ldots \ldots \ldots \ldots$

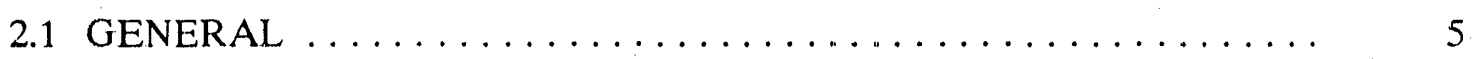

2.2 PROGRAM POLICY AND DIRECTIONS $\ldots \ldots \ldots \ldots \ldots \ldots \ldots \ldots$

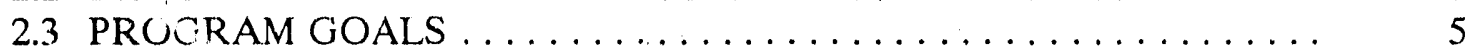

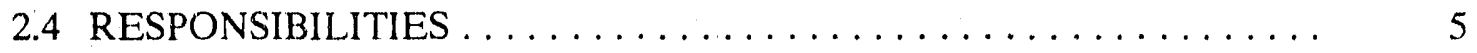

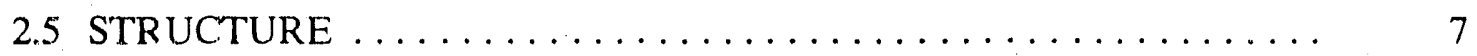

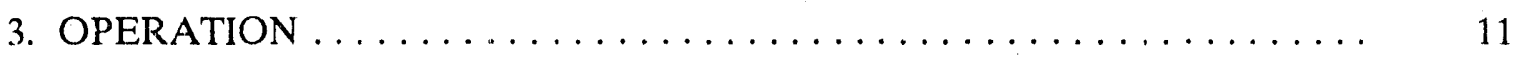

3.1 CALIBRATION $\ldots \ldots \ldots \ldots \ldots \ldots \ldots \ldots \ldots \ldots \ldots \ldots \ldots \ldots \ldots$

3.2 EXCEPTIONS TO PERIODIC CALIBRATION REQUIREMENTS ... 11

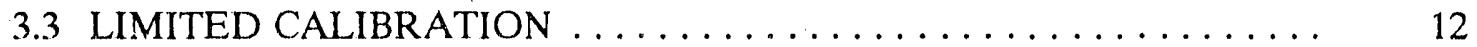

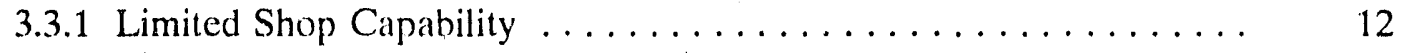

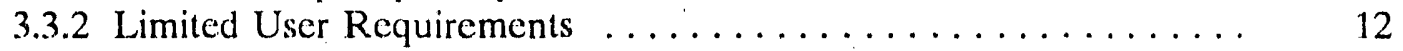

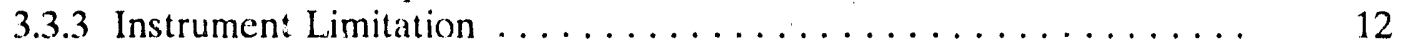

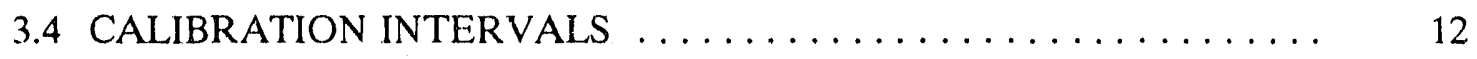

3.5 CALIBRATION GRACE PERIOD $\ldots \ldots \ldots \ldots \ldots \ldots \ldots \ldots \ldots \ldots$

3.6 CALIBRATION DEVIATIONS $\ldots \ldots \ldots \ldots \ldots \ldots \ldots \ldots \ldots \ldots \ldots \ldots$

3.7 CARE OF MEASURING AND TEST EQUIPMENT . . . . . . . . . 13

3.8 MEASURING AND TEST EQUIPMENT WARRAIVTIES . . . . . . . . 14

4. CALIBRATION FORMS AND LABELS $\ldots \ldots \ldots \ldots \ldots \ldots \ldots \ldots \ldots$

4.1 PREPARATION AND USE OF CALIBRATION FORMS
AND LABELS $\ldots \ldots \ldots \ldots \ldots \ldots \ldots \ldots \ldots \ldots \ldots \ldots \ldots \ldots \ldots \ldots$

4.2 MEASURING AND TEST EQUIPMENT CALIBRATION LABEL . . 15

4.3 PLACEMENT OF CALIBRATION LABELS . . . . . . . . . . . . . . 16

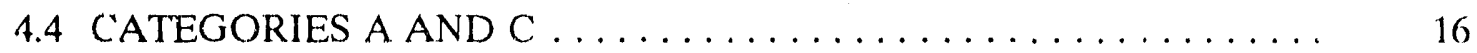

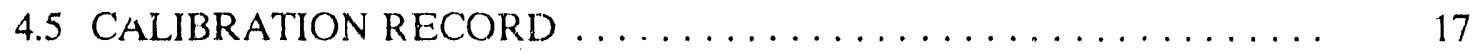

4.6 MEASURING AND TEST EQUIPMENT CALIBRATION
CORRECTION RECORD $\ldots \ldots \ldots \ldots \ldots \ldots \ldots \ldots \ldots \ldots \ldots \ldots \ldots \ldots$

4.7 COMPUTERIZED AND MANUALLY PREPARED
CALIBRATION DATA $\ldots \ldots \ldots \ldots \ldots \ldots \ldots \ldots \ldots \ldots \ldots \ldots$ 


\section{CONTENTS' (continued)}

\section{Page}

5. CALIBRATION REPORTS $\ldots \ldots \ldots \ldots \ldots \ldots \ldots \ldots \ldots \ldots \ldots \ldots \ldots \ldots \ldots \ldots$

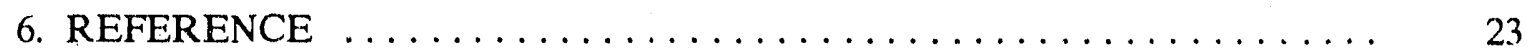




\section{LIST OF FIGURES}

Page

1. Measurement traceability under the instrument Calibration Program . . . . . . 8

2. Diagram of instrument calibration procedure $\ldots \ldots \ldots \ldots \ldots$

3. Measuring and test equipment calibration identification label $\ldots \ldots \ldots \ldots$

4. Category A calibration label $\ldots \ldots \ldots \ldots \ldots \ldots \ldots \ldots \ldots \ldots \ldots \ldots \ldots$

5. Category $\mathrm{C}$ calibration label $\ldots \ldots \ldots \ldots \ldots \ldots \ldots \ldots \ldots \ldots \ldots \ldots \ldots \ldots$

6. Front side of Instrumentation and Controls Division calibration record . . . . . 18 


\begin{abstract}
This document describes the methods and procedures for management of the Instrumentation and Controls I\&C Division Maintenance Management Department Calibration Program.

The implementation of the Program rests primarily with the I\&C Division Maintenance shops and the services supplied by the I\&C Division Metrology Research and Development Laboratory. An important aspect of the overall program is the user or customer interface. Support activities are initiated and maintained through an active participation of operations and research organizations. It is imperative that all parties involved in the process maintain timely and effective dialogue to ensure that the process is adequate for the needs of the Laboratory.
\end{abstract}




\section{INTRODUCTION}

This document describes the methods and procedures for management of the Oak Ridge National Laboratory (ORNL) Instrumentation \& Controls (I\&C) Division Maintenance Management Department (MMD) Calibration Program. All personnel who have responsibility for calibration of equipment shall be familiar with the calibration program described in this document.

\subsection{GENERAL}

The primary function of the MMD Calibration Program is to ensure the measurement integrity of all instruments used to provide quantitative or qualitative data to meet program objectives and ensure safe, reliable, cost-effective, and timely operation.

The MMD Calibration Program includes measurement standards and equipment, technical personnel, plant-wide work centers, measurement equipment users, calibration data, and integrated planning combined in a structured program to ensure the reliability and accuracy of instruments, systems, subsystems, and equipment.

The Calibration Program is a planned, systematic schedule of all actions necessary to provide confidence that equipment used to make measurements or quality judgments conforms to established technical requirements. It ensures measurement traceability to the National Institute of Standards and Technology (NIST) or other nationally recognized standards. Measurements in the mechanical, electrical, electronics, chemical, and nuclear fields are included.

The contents of this document are reviewed and revised biennially by the calibration committee appointed by the MMD department head. The plan is distributed according to the current distribution list at the end of this document.

\subsection{DEFINITIONS}

The following definitions are provided to ensure uniform understanding of selected terms as they are used in this document.

A. Calibration: Systematic comparison between measurement standards of known characteristics and accuracy and a test item to detect, correlate, adjust, and report any inaccuracy in the indication of the item under calibration.

B. Calibration (limited): Calibration of measuring and test equipment (M\&TE) at a level of accuracy less than that specified in the authorized calibration procedure or M\&TE manufacturer's specifications, but at an acceptable functional level.

C. Calibration Record: Record prepared for a specific item to show the actual value of the parameter(s) certified.

D. Correction Table: Table of values prepared for a specific: item to show the corrections necessary to obtain actual values. 


\section{E. Equipment Types:}

1. Measuring and Test Equipment (M\&TE): Devices or systems used to calibrate, measure, gauge, test, inspect, diagnose, or otherwise examine materials, supplies, and equipment to determine compliance with design, specifications, or other technical requirements.

2. Reference Standards: Standards (i.e., primary, secondary, and working standards, where appropriate) used in a calibration program. These standards establish the basic accuracy limits for that program.

3. Working Standards: Devices used to calibrate end-use instrumentation or lower order working standards.

4. Fundamental Standard: Standard established by physical properties or materials or by physical laws.

5. Equipment Not Requiring Calibration: Equipment that does not require calibration or other comparison traceable to the National Institute of Standards and Technology (NIST).

F. Custodian/User: Person or organization responsible for the use and care of a specific instrument.

G. Work Centers: Maintenance shops responsible for repairing, calibrating, and certifying M\&TE.

H. Metrology: Science that deals with precision measurement of physical quantities and establishment of units, standards, and experimental techniques for measurement.

I. Metrology Research and Development Laboratory (MRDL): Laboratory maintained in the I\&C Division to provide specialized calibration and Metrology Engineering services.

J. Traceability: Ability to relate individual measurement results to national standards or nationally accepted measurement systems through an unbroken chain or direct comparison.

K. Instrument Accuracy: Measure of the degree by which the actual output of a device approximates the output of an ideal device nominally performing the same function.

L. Measurement Accuracy: Measure of the difference between the result of a measurcinent and the true value of the quantity being measured; measurement accuracy is affected by many things including instrument accuracy, experimental techniques, and statistical data analysis.

M. In Calibration: Device is assumed to be in calibration when it has an unexpired calibration label and the device shows no signs of having been subjected to abuse or an environment that may have invalidated its calibration. 
N. Nuclear Facility: Facility whose operations involve radioactive materials in such form and quantity that a significant nuclear hazard potentially exists to the employees or the general public. Included are facilities that: (1) produce, process, or store radioactive liquid or solid waste, fissionable materials, or radioactive gases;

(2) conduct separations operations; (3) conduct irradiated materials inspection, fuel fabrication, decontamination, or recovery operations; or (4) conduct fuel enrichment operations. Incidental use of radioactive matcrials in a facility operation (c.g., check sources, and X-ray machines) does not necessarily require the facility to be included in this definition. Accelerators and their operations are not included. 


\section{PROGRAM ORGANIZATION}

\subsection{GENERAL}

The purpose of the MMD calibration plan is to provide a uniform and documented calibration program so that all M\&TE used in support of ORNL systems and experiments can be maintained at a high level oi confidence.

\subsection{PROGRAM POLICY AND DIRECTIONS}

This plan complies with and expands upon ORNL quality assurance procedures which defines the requirements for control and calibration of M\&TE.

\subsection{PROGRAM GOALS}

A. Inventory, on request, M\&TE anc assign to the appropriate category for future control and record keeping.

B. Encourage the acquisition and control of operating and technical manuals of all M\&TE that requires calibration.

C. Select, maintain, and document suitable equipment necessary to sustain an effective calibration program.

D. Establish written procedures to standardize the calibration process as needed.

\subsection{RESPONSIBILITIES}

A. Maintenance Management Department

1. Provides necessary training to ensure that calibration technicians have adequate knowledge of the standards used and the instruments that require calibration.

2. Maintains the Maintenance Accountability, Jobs, and Inventory Control System (MAJIC), specified in Sect. 10 of MIDAS, ${ }^{1}$ a data base syste for calibration recall scheduling, service records, and status reports.

B. Metrology Laboratory

1. Maintains reference standards and ensures measurement traceability to NIiTT or other nationally recognized standards and provides specialized services for calibration of unique equipment.

2. Provides calibration services for working standards. 
3. Provides Metrology Engineering services.

C. Shop Supervisor/Technical Support

1. Assists in ev.luating calibration data and prepares correction charts if necessary or requested.

2. Implements the MMD Calibration Program.

3. Reviews manufacturers' calibration procedures for adequacy.

4. Prepares calibration procedures for M\&TE when existing procedures are determined to be inadequate or unavailab!e.

5. Maintains inventory and calibration records.

6. Removes from inventory items reported lost, salvaged, or transferred.

7. Notifies custodian/user when out-of-tolerance conditions occur.

8. Shop supervisor ensures that personnel performing calibrations on M\&TE are familiar with the calibration plan and that personnel training is documented in the MMD training data base.

9. Ensures that "as-found" and "as-left" calibration data are documented, stored, and retrievable.

10. Ensures that calibration information for each calibration activity is provided to the custodian/user unless otherwise directed.

D. Technician

1. Verifies that standards are in calibration and in good working condition before use.

2. Checks calibration and records "as-found" data before adjustments are made.

3. Records "as-left" calibration data. Prepares calibration and correction charts when appropriate.

4. Shall be aware of systern requirements and report any discrepancies.

5. Shall report to the facility manager and shop supervisor out-of-tolerance conditions. 
E. Custodian/User

The responsibilities of the custodian/user are defined in QA-L-12-100 and listed in this plan for reference purposes only:

1. Identifies and documents equipment classified as M\&TE. Revicws the application of M\&TE for proper type, range, accuracy, and tolerance with the quality assurance specialist (QAS) and the appropriate calibration organization.

2. Categorizes the M\&TE as category A, B, or C.

3. Establishes and documents the calibration schedule for M\&TE.

4. For category B M\&TE, in consultation with the appropriate calibration organization, agrees on calibration procedures, certification range, recalibration and preventive maintenance interval, and accuracy to be achieved.

5. Enters the designated category B M\&TE into the programmed calibration and maintenance recall system of the appropriate calibration organization and ensures that the agreed upon calibration is implemented.

6. Affixes category $\mathrm{A}$ (when required) and $\mathrm{C}$ calibration labels.

7. Ensures that adequate calibration data records are maintained for M\&TE.

8. Ensures that out-of-calibration M\&TE devices are tagged and/or segregated and not used until recalibrated.

9. Evaluates and documents the validity of previous inspection or test results and the acceptability of items when M\&TE is found to be out of calibration.

\subsection{STRUCTURE}

The MMD Calıbration Program involves all persons who use M\&TE in their work. The first responsibility is upon the M\&TE custodian/user, who must ensure that all M\&TE used to generate quality data is "in calibration."

Figure 1 depicts the measurement traceability of the Calibration Program. A calibration operation should be performed as close to the user's location as possible. Instruments in work centers are calibrated in a centralized calibration facility or in the Standards Laboratory of MRDL. Centralized calibration standards are calibrated by the Standards Laboratory or other authorized calibration facility that maintains reference standards of measurement of known accuracy traceable to the NIST standard.

Functions such as instrument recall, data analysis, calibration procedures development, and state-of-the-art advancements must be included in any calibration program plan. The flow of the MMD instrument calibration program (Fig. 2) provides centralized control and surveillance. 


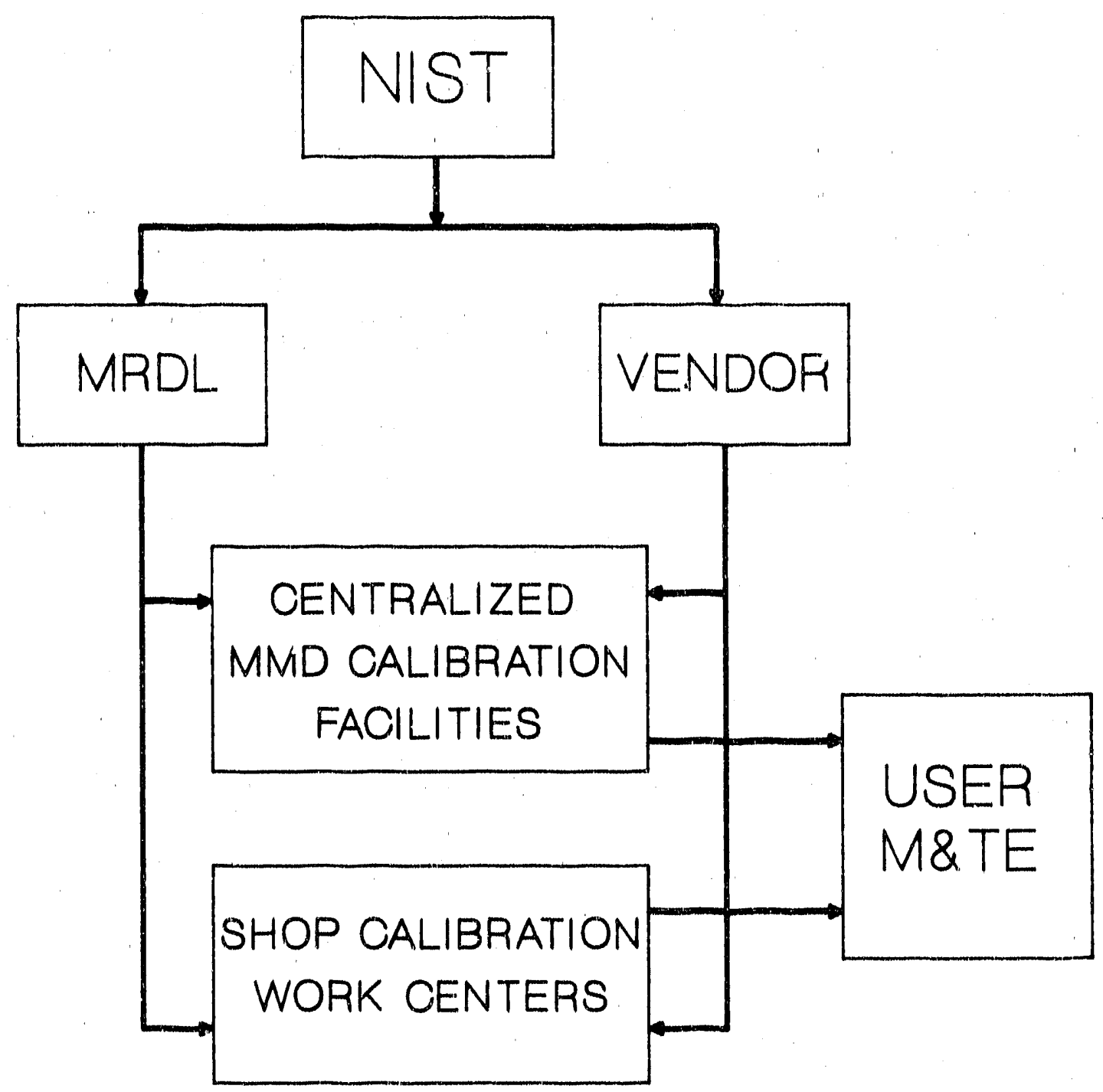

Fig. 1. Measure . tent traceability under the Instrument Calibration Program. (N'ST = National Institute of Standards and Technology; MRDL $=$ Metrology Research and Development Laboratory; MMD = Maintenance Management Department; and M\&TE = measuring and testing equipment.) 


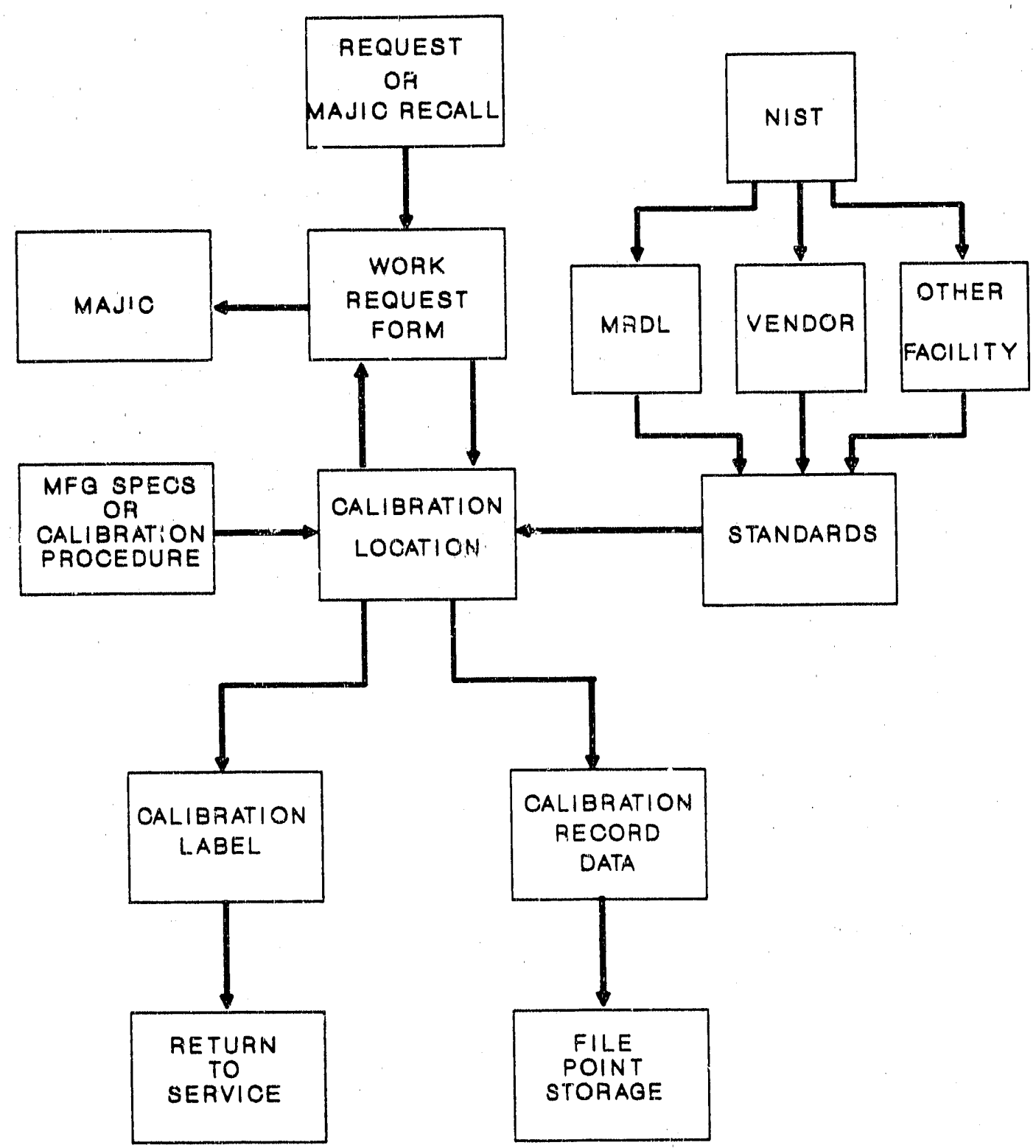

Fig. 2. Diagram of instrument calibration procedure. (MAJIC $=$ Maintenance Accountability, Jobs, and Inventory Control System; NIST = National Institute of Standards and Technology; MRDL = Metrology Research and Development Laboratory; and MFG SPECS = manufacturer's specifications.) 


\section{OPERATION}

\subsection{CALIBRATION}

Maintenance shops, which are staffed ard operated by the Maintenance Management Department, are responsible for repairin ${ }_{b}$ drd/or calibrating all M\&TE assigned to their area of responsibility. Calibration inter als and responsibilities for maintenance or calibration of standarus and M\&TE are identified in this document. M\&TE that are used to make measurements critical to the test and alignment of uperational systems and equipment are calibrated at specific intervals or before use.

A. To ensure a valid and accurate calibration, (1) an approved calibration procedure must be specifically referenced oy (2) knowledgeable personnel using (3) equipment specified in the procedure (or adequate substitules with required functions, ranges, and accuracies). Draft procedures may be used to perform calibrations, provided the procedures have been marked "DRAFT" and approved by the responsible MMD supervisor. Final approval of calibration procedures require signature of the MMD department head and division guality assurance specialist (QAS). If no procedure is available for an M\&TE item, venúor- or industry-approved general procedures will be used to calibrate the M\&TE after the procedures are reviewed for adequacy.

B. Although the maintenance supervisor is expected to assist the custodian/user in maintenance and calibration of the equipment, the decision to calibrate and the limits of calibration are the responsibility of the custodian/user.

C. The equipment required to calibrate an item shall be listed in the individual calibration procedure under the heading "REQUIREMENT(S)." Other approved equipment having the necess ry characteristics such as functions, ranges, and accuracies may be used to perform a calibration even though that equipment may not have all of the characteristics of the listed item. The accuracy (or uncertainty) of the measurement process srecified in the procedure shall te better than the specified accuracy of the item being calibrated by at least 4:1. Modification of procedural steps is authorized by the supervisor when subs tute equipment is used, provided the specific parameters of the calibration procedure are not compromised.

It is important to note that good judgment must always be applied in calibrating and certifying equipment. Whether or not a piece of stendard M\&TF is of adequate quality and accuracy to make reasonaule measurements should be apparent to an experienced technician or supervisor. An essential crit non for certification is that the equipment in question be sufficiently stable and acc'srate to perform its intended function.

\subsection{EXCEPTIONS TO PERIODIC CALIBRATION REQUIREMENTS}

Certain types of M\&TE do not require periodic calibration: M\&TE that is seldom used but must be calibrated before use and M\&TE that requires only an initial calibration. Certain types of M\&TE identified as "calibration not required" (CNR), category A, do not require calibration, because they do not provide quartitative measurement information 
(i.e., information obtained by its use is of a gross nature such as verifying power on or off). The work center supervisor and the M\&TE custodian/user are responsible for determining calibration exceptions.

\subsection{LIMITED CALIBRATION}

In some siturtions, the work center may be awhorized to perform a limited calibration. Authorization for a limited calibration shall be the joint responsibility of the work center supervisor and the equipment custodian/user.

\subsubsection{Limited Shop Capability}

When a work center does not have the capability to calibrate the full range of specifications contained in the calibration procedure, the work center supervisor sha!l advise the custodian/user of the extent of available services. The custodian/user shall then determine whether the available services will meet their measurement needs. If the limited calibration services will not meet the needs, the custodian/user shall advise the work center, and action shall be taken to obtain the necessary capabilities.

\subsubsection{Limited User Requirements}

When a user requires less than the full capability of the M\&TE, the user shall specify the desired calibration points or ranges to the responsible work center. The work center supervisor or calibration technician shall clearly identify the certified points or ranges on the calibration record and shall provide a copy of the calibration data to the custodian/user unless otherwise directed.

\subsubsection{Instrument Limitation}

When a function, range, or specification on a multifunction instrument cannot be economically restored to its original design specifications, the work center supervisor shall advise the custodian/user of the condition. The custodian/user shall then determine whether the missing function is necessary and whether to permit a limited calibration or to replace the item.

In any case, the category B label (Sect. 4.2) must be marked "SPECIAL" if the M\&TE calibration is limited in any way.

\subsection{CAIIIBRATION INTERVALS}

The established calibration interval is determined by the length of time the equipment should $\mathrm{m}$ aintain its accuracy and perform its intended function. These intervals are established and modified as necessary. 
A. The maximum calibration interval for new M\&TE is 12 months if no interval is prescribed by the manufacturer. A calibration interval may be changed by as a result of activity, applications, or maintenance history. Recall may be staggered to maintain an even work load in the work center. M\&TE users may request shorter intervals between calibrations to meet system or project requirements.

B. M\&TE custodians/users may request recalibration any time there is reason to question the accuracy of an instrument. Items that have been exposed to rough handling, overload, or other severe conditions shall be immediately identified and recalibrated before further use regardless of the scheduled calibration date.

\subsection{CALIBRATION GRACE PERIOD}

The calibration of equipment shall be performed in accordance with a predetermined schedule. Extensions to the interval (Grace Perions) up to 30 days may be given. If the 30-day grace period is preempted by a DOE Order, law, or regulation, the exception shall be documented and the now requirements defined.

\subsection{CALIBRATION DEVIATIONS}

The Deviation Request, Form UCN-5458A, shall be completed in accordance with instructions on the back of the form for the following situations.

A. Instrument is to be removed from calibration recall by the custodian/user.

B. Instrument calibration is refused by custodian/user but instrument is not to be removed from recall system.

C. Calibration period is extended as a result of workload considerations and/or equipment is unavailable at scheduled recall date.

The work center supervisor shall:

A. complete the Deviation Request form;

B. file a copy of the completed form at the work center and submit a copy to the custodian/user for signature; and

C. upon receipt of the signed copy from the custodian/user, replace the file copy with the signed copy.

\subsection{CARE OF MEASURING AND TEST ECUIPMENT}

Custodians/users are responsible for the proper handling, storage, care, use, and cleanliness of M\&'TE. 
A. Items of M\&TE shall be handled as "delicate instruments" regardless of physical appearance.

B. It is the responsibility of the custodian/user to ensure that M\&TE is properly cleaned and tagged to indicate freedom from all contamination before transport to the responsible work center.

C. Calibration work centers shall tag or segregate out-of-calibration M\&TE.

\subsection{MEASURING AND TEST EQUIPMENT WARRANTIES}

M\&TE is frequently covered by a provisional warranty from the manufacturer. Such warranties vary in length of coverage and specific service or maintenance coverage as well as in provision for correction of deficiencies in design, material, or workmanship that does not meet M\&TE performance specifications.

A. The work center supervisor is authorized to use the manufacturer's calibration certification on new M\&TE to establish the first calibration cycle and shall affix a category $\mathrm{B}$ label, provided it can be verified that the device was in acceptable condition when received and put into service.

B. Upon receipt of new equipment, the work center shall:

1. determine warranty expiration date,

2. calibrate equipment if required, and

3. defective equipment under warranty shall be returned to the custodian/user with technical information relative to the defect or returned to the vendor for warranty repair. 


\section{CALIBRATION FORMS AND LABELS}

\subsection{PREPARATION AND USE OF CALIBRATION FORMS AND LABELS}

All instruments for which the I\&C Division has maintenance responsibility shall be identified with a distinctive identification number, which shall be recorded according to the inventory requirements specified in Sect. 10 of MIDAS.!

Labels shall be located on equipment such that the labels are visible without removing equipment from mountings or from normal service.

Calibration labels shall be able to withstand the effects of the operating environment for the time interval between calibrations and yet be replaceable as needed.

All writing on labels shall be in ink of a type suitable for withstanding the environment to which the labeled equipment will be subjected and for the time intervals required.

Under no circumstances shall information on calibration labels be marked over, marked out or changed. When a change in information is required, the old label shall be removed and destroyed and a new label completed and affixed to the instrument.

\subsection{MEASURING AND 'TEST EQUIPMENT CALIBRATION LABEL}

\section{Category B. (calibration recall program)}

The M\&TE calibration label (UCN-14883) shown in Fig. 3 shall be completed and affixed to standards and M\&TE calibrated by the responsible work center. If labels or tags are not practical, a facility log book or technical notebook may be used to record calibration status. Labeis shall not be replaced except by persons authorized to perform calibrations. The calibration technician or other authorized person shall complete the label in nonsmearing permanent ink in the following manner:

A. Identification Number: Enter the identification (ID) number recorded in the MIDAS $^{1}$ System on the equipment being calibrated.

B. Date: Enter the date the M\&TE was calibrated. When authorized to use manufacturer's calibration, use the date on the manufacturer's certificate rather than the date the unit was placed into service.

C. Calibrated By: The badge number of the calibration technician shall be entered in this block. The I\&C calibration technician shall enter a check in the block that appropriately identifies the work center.

D. Special: This block shall be used to bring to the attention of the user that the M\&TE has a limited or special-case calibration. 


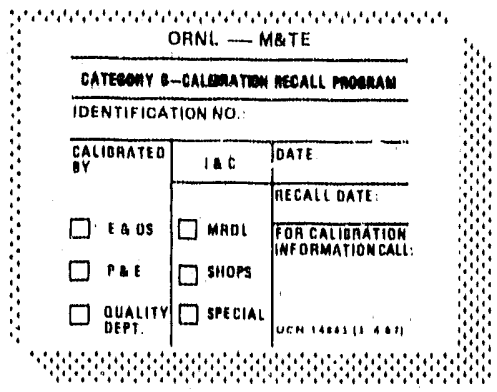

Fig. 3. Measuring and test equipment calibration identification label.

E. Recall Date: Enter the month and year in which the equipment is due for calibration. The calibration due date shall be computed from the assigned calibration interval and start month on instrument inventory. Items calibrated and not on program recall shall be marked "NONE."

F. For Calibration Information Call: Enter the phone number of the work center performing the calibration.

\subsection{PLACEMENT OF CALIBRATION LABELS}

Calibration labels shall be affixed to a clean surface in a conspicuous area on the equipment. On small items, the label may be affixed to a plain manila tag and attached to the equipment. Calibration labels may be affixed to the side or back panel of interchangeable plug-ins. If the label cannot be placed on the front panel or if a tag would interfere with the operation of the plug-in, the size of the tag may be reduced by trimming, but the ID number and recall date shall be retained; all out-dated labels shall be removed. On complex M\&TE such as test stands or checkout consoles, one calibration label for the end item will suffice for all items that are an integral part of the equipment

On M\&TE where the calibration label cannot be affixed, other methods shall be used for indicating calibration.

\subsection{CATEGORIES A AND C}

\section{Category A (calibration not required)}

Tags or labels indicating calibration status may be attached directly to N \& TE devices and systems at the discretion of the custodian/user, who is responsible for identification and labeling. 
The category A label shown in Fig. 4 shall be affixed to those items of M\&TE identified as "calibration not required" (CNR). The organization that owns CNR equipment is responsible for affixing this label to the M\&TE.

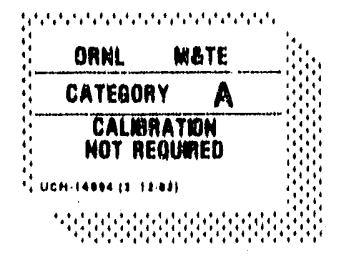

Fig. 4. Category A calibration labcl.

Category $\mathrm{C}$ (calibration by user)

The label shown in Fig. 5 shall be affixed to those items of M\&TE identified as category $\mathrm{C}$, which indicates that the equipment is to be calibrated by or upon request of the custodian/user, who is responsible for identification and labeling.

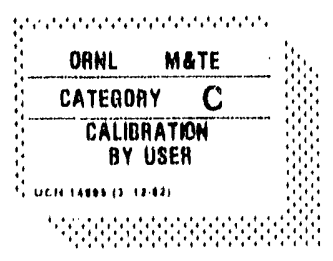

Fig. 5. Category $\mathrm{C}$ calibration labcl.

\subsection{CALIBRATION RECORD}

The I\&C calibration record (Fig. 6) shall be completed for M\&TE calibrated by the work center technician to show the actual values of the parameters checked. The work center shall store and be able to retrieve the calibration record, and a copy may be attached to the equipment. The calibration record shall be legible, neat, and unaltered. 

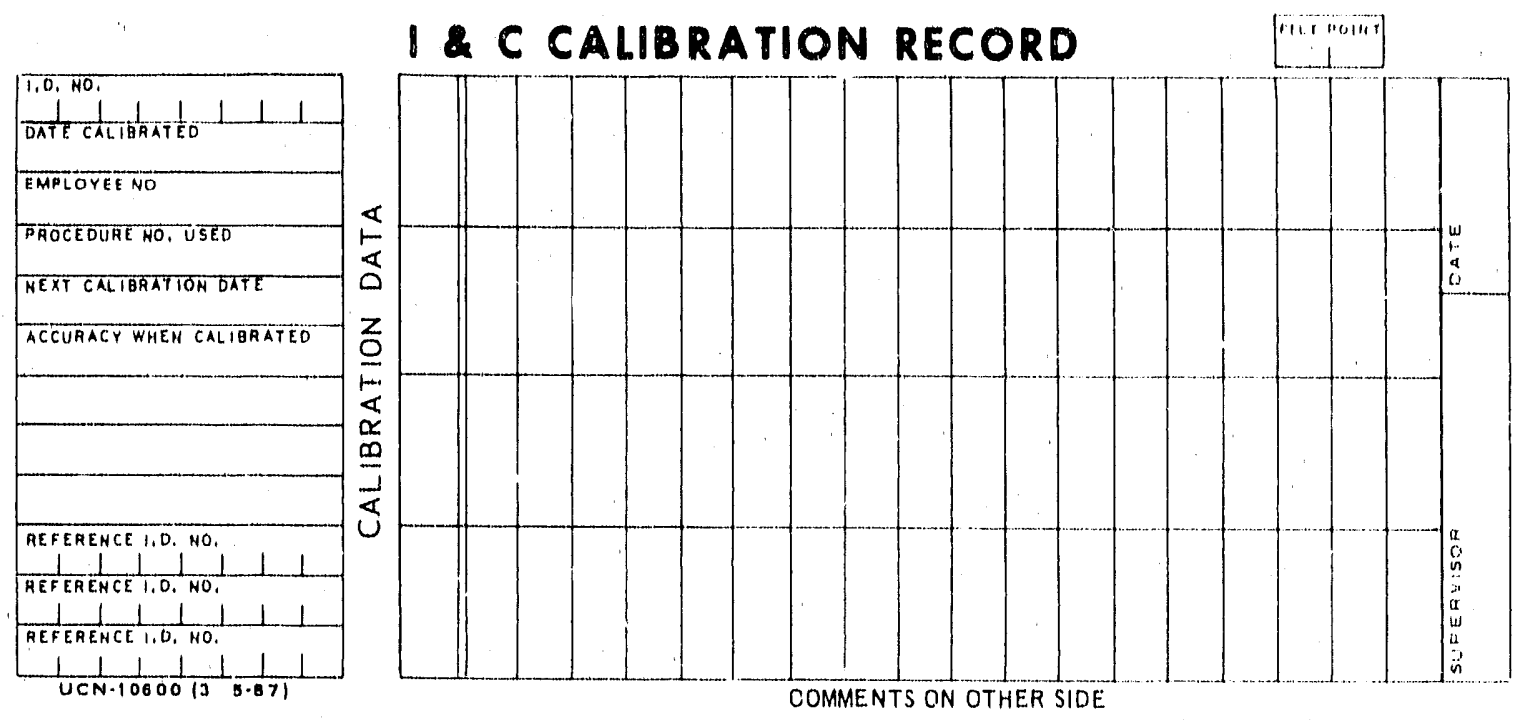

Fig. 6. Front of I\&C Calibration Record (card shown smaller than actual size).

The calibration record shall be completed as foll ws:

A. Identification Number: Enter the ID number assibirited the M\&'TE.

B. Date Calibrated: Enter the date on which the M\&TE was calibrated.

C. Employee Number: The badge number of the calibration technician shall be entered in this block.

D. Procedure Number Used: Enter the calibration procedure number assigned to the M\&TE or the data used to perform the calibration.

E. Next Calibration Date: Enter the next calibration due date, determined by the assigned calibration interval as described in Sect. 4.2.e.

F. Accuracy When Calibrated: Accuracy shall comply with manulacturer's specifications unless otherwise noted. For limited calibrations, identify the parameter(s) calibrated and accuracy required.

G. Reference Identification Number: Enter the ID number(s) of the standard(s) used to perform the calibration.

H. Calibration Data: Indicate appropriate column headings and units for the calibration parameters. Recorded information shall include "as-found" and "as-left" data as well as errors calculated. 
I. File Point: Enter the appropriate file point assig id to the work center performing the calibration.

The work center super/isor or a designated representative shall sign and date the calibration record when the technician completes the calibration.

When the calibration data cannot be entered on this form, all other pertinent information shall be entered with a note across the data entries indicating where the actual calibration information is filed.

NOTE: Enter the work request number for the job in the space above the M\&TE ID number.

\subsection{MEASURING AND TEST EQUIPMENT CALIBRATION CORRECTION RECORD}

A chart or graph shall be made available when requested by the using organization to show the correction that must be applied to the indicated reading to obtain the actual value.

\subsection{COMPUTERIZED AND MANUALLY PREPARED CALIBRATION DATA}

Computerized or manually prepared calibration or correction data may be used as the calibration record, provided a calibration record (UCN-10600) is completed with a notation identifying the location of the calibration data. 


\section{CALIBRATION REPORTS}

The MMD MAJIC System collects maintenance information on M\&TE selected for calibration recall and provides computer-generated reports for control. Refer to the MIDAS manual ${ }^{1}$ for calibration reports available. 


\section{REFERENCE}

1. C. 'T. Stansberry, S. M. Odom, and C. D. Martin, Maintenance Information and Data Acquisition System (MIDAS), ORNL/TM-11287, Oak Ridge National Laboratory, Oak Ridge, Tenn., 1989. 

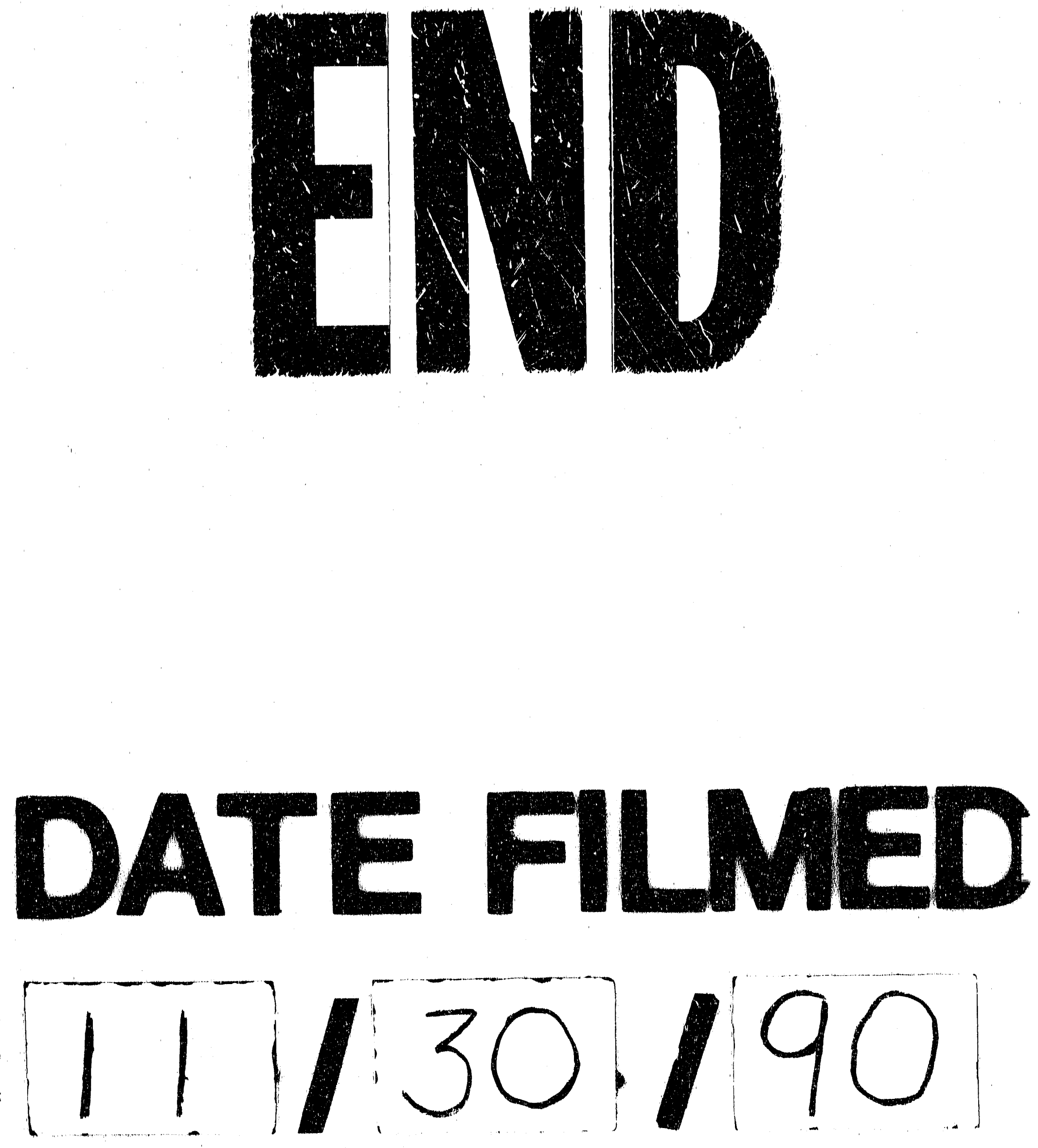
